\title{
COVID-19: instruments for the allocation of mechanical ventilators-a narrative review
}



\author{
Marcelo José dos Santos ${ }^{1,2^{*}}$ (D, Maristela Santini Martins ${ }^{1}$, Fabiana Lopes Pereira Santana ${ }^{1}$, \\ Maria Carolina Silvano Pacheco Corrêa Furtado', Fabiana Cristina Bazana Remédio Miname', \\ Rafael Rodrigo da Silva Pimentel ${ }^{1}$, Ágata Nunes Brito ${ }^{1}$, Patrick Schneider ${ }^{1}$, Edson Silva dos Santos ${ }^{1}$ and \\ Luciane Hupalo da Silva ${ }^{1}$
}

\begin{abstract}
After the World Health Organization declared COVID-19 to be a pandemic, the elaboration of comprehensive and preventive public policies became important in order to stop the spread of the disease. However, insufficient or ineffective measures may have placed health professionals and services in the position of having to allocate mechanical ventilators. This study aimed to identify instruments, analyze their structures, and present the main criteria used in the screening protocols, in order to help the development of guidelines and policies for the allocation of mechanical ventilators in the COVID-19 pandemic. The instruments have a low level of scientific evidence, and, in general, are structured by various clinical, non-clinical, and tiebreaker criteria that contain ethical aspects. Few instruments included public participation in their construction or validation. We believe that the elaboration of these guidelines cannot be restricted to specialists as this question involves ethical considerations which make the participation of the population necessary. Finally, we propose seventeen elements that can support the construction of screening protocols in the COVID-19 pandemic.
\end{abstract}

Keywords: Pandemics, Health care rationing, Decision making, Ethics

\section{Introduction}

SARS-CoV-2 is a highly transmissible virus that causes COVID-19, a disease that can evolve to a severe clinical state due to a chronic systemic inflammatory response which can lead to acute respiratory distress syndrome [1-3].

After the World Health Organization declared COVID-19 to be a pandemic [4], new public health policies aimed at protecting the population became essential. However, the adoption of ineffective public policies may have contributed to the increase in the number of

\footnotetext{
* Correspondence: mjosan1975@usp.br

'Research Group "Bioethics and Administration: Teaching and Health Care", Nursing School of University of São Paulo, São Paulo, SP, Brazil

${ }^{2}$ Departamento de Orientação Profissional, Escola de Enfermagem da Universidade de São Paulo, Rua Dr. Enéas de Carvalho Aguiar, 419, CEP 05403-000 Cerqueira Cesar, São Paulo, SP, Brazil
}

cases and the consequent overload of the health system $[5,6]$.

Studies show that 17 to $35 \%$ of patients affected by this disease require hospitalization in intensive care units $[7,8]$ and that from 9 to $19 \%$ need invasive mechanical ventilation (IMV) [7, 9], during a period which can vary from 2 to 4 weeks [10]. Estimates indicate that countries such as the USA [11, 12] and Brazil [13] may not have enough invasive mechanical ventilators to attend all of the patients who need this resource for COVID-19 treatment. This was the situation in Italy, where doctors had to decide which patient would receive IMV [14]. Decision making in the allocation of scarce resources in pandemics, in addition to directly impacting people's lives, can lead the professional to a situation of moral suffering [15].

(c) The Author(s). 2020 Open Access This article is licensed under a Creative Commons Attribution 4.0 International License, which permits use, sharing, adaptation, distribution and reproduction in any medium or format, as long as you give appropriate credit to the original author(s) and the source, provide a link to the Creative Commons licence, and indicate if changes were made. The images or other third party material in this article are included in the article's Creative Commons licence, unless indicated otherwise in a credit line to the material. If material is not included in the article's Creative Commons licence and your intended use is not permitted by statutory regulation or exceeds the permitted use, you will need to obtain permission directly from the copyright holder. To view a copy of this licence, visit http://creativecommons.org/licenses/by/4.0/ The Creative Commons Public Domain Dedication waiver (http://creativecommons.org/publicdomain/zero/1.0/) applies to the data made available in this article, unless otherwise stated in a credit line to the data. 
Given this scenario, it is urgent to build managerial and ethical strategies in order to ration scarce resources [16]. Thus, this study aims to identify instruments, analyze their structures, and present the main criteria used in the screening protocols in order to help the development of guidelines and policies for the allocation of mechanical ventilators in the face of the COVID-19 pandemic.

\section{Methods}

The synthesis of evidence was performed based on articles that presented instruments for decision making in the allocation of mechanical ventilators, in contexts of respiratory pandemics. The databases searched were ASSIA, Embase, PubMed, Scopus, and academic platform ScienceDirect. An additional file shows the exact search strategies (see Additional file 1). Only articles with the context of respiratory pandemics, primary studies, theoretical, opinion, and consensus were included, regardless of language and date of publication. We screened the results on the title and abstract for relevant information. The selected articles were read in full. From the articles and reviews found in this search, we used the snowball strategy, checking useful references and similar articles and retrieving those that were considered relevant. Guidelines from international organizations were used to identify more articles. This search was last updated on April 15, 2020.

\section{Instruments}

The development of instruments to allocate scarce resources increases in periods of pandemics, as occurred with influenza [ 17-24], with severe respiratory distress syndrome (SARS) $[18,23]$ and nowadays with COVID19 [25-27].

After the SARS outbreak in 2003 [28], a pioneering guideline for triage in intensive care in pandemics [29] was developed and published, and this became a reference for the development of new instruments [17-27, 30-32]. An additional file shows a summary of each instrument identified in this investigation in more detail (see Additional file 2).

Any guidelines take into account the expected prognosis. Thus, data on the prognosis of patients with COVID-19 is needed to update and improve existing protocols. However, these data may be unavailable due to the short period since the onset of the disease [33].

Some of the instruments found in this study $[17,20-27$, 29-31], direct screening for access to intensive care (intensive care beds, hemodynamic and respiratory support, antibiotic therapy, renal replacement therapy), while others [18, 19 , 32] deal specifically with the allocation of invasive mechanical ventilators.
The construction of these instruments was based on expert opinions and consensus. To guarantee quality and rigor in this process, Ornelas et al. [34] systematized a method composed of the domains: methodology, usability, validity, bias, and summative. In order to assess the instruments included in this review, a score was established, based on the usability domain [34], for each instrument presented (Table 1).

In general, the structure of the instruments includes clinical, non-clinical, and tiebreaker criteria, which are permeated by ethical aspects for decision making in the allocation of scarce resources [17-27, 29-32] (Table 2).

\section{Clinical criteria}

The clinical evaluation criteria for screening patients in situations of scarcity of resources aim to identify the patients most likely to survive hospital discharge [35]. The prognosis is one of the parameters used to support decision making in the allocation of intensive care in order to balance benefits and harm, in addition to determining when treatment becomes futile [36]. However, the prognostic assessment carried out by different members of the same multidisciplinary team may reach different conclusions $[37,38]$. It is, therefore, an imprecise parameter [39].

In order to increase the accuracy and safety of the prognosis, disease severity scores, and clinical forecasting models have been developed, but so far, they have not been completely satisfactory [40]. It is important to emphasize that in order to determine the prognosis, it is not recommended to consider only the probability of survival, since measures of functional results and quality of life are also aspects considered essential for both patients and society [41].

In this review, the instruments which were found used, in order to determine the probability of survival, the Sequential Organ Failure Assessment score (SOFA) [18-23, 25, 26, 29-32], the Laboratory Acute Physiology Score (LAPS2) [26], the calculation for the prediction of the Mortality Risk Index associated with the number of days on mechanical ventilation [24], and/or the Pediatric Logistic Organ Dysfunction 2 (PELOD-2) [32].

SOFA was the most frequently used instrument for decision making in the allocation of critical care [18-23, 25, 26, 29-32]. After the experiences with the H1N1 pandemic, the use of this tool as a screening strategy gained popularity, which is attributed to the objectivity of the instrument, its low cost, and its use of complementary exams which are not complex [18-23, 25, 26, 29-32].

However, the use of SOFA to screen COVID-19 patients has been questioned [33] and not recommended [42]. Some studies [43-45] show that, due to the cutoff points adopted in some of the protocols, SOFA may not 
Table 1 Presentation of instruments for decision-making

\begin{tabular}{|c|c|c|c|c|c|c|c|c|c|}
\hline Authors & Country/year & $\begin{array}{l}\text { Community } \\
\text { participation }\end{array}$ & Clinical Instrument & Patient & Reassessment & $\begin{array}{l}\text { Stratification } \\
\text { Criteria }\end{array}$ & Tiebreakers & $\begin{array}{l}\text { Ventilation } \\
\text { withdrawal }\end{array}$ & $u^{c}$ \\
\hline Ardagh [17] & $\mathrm{NZ} / 2006$ & No & Uninformed & Adult/pediatric & Uninformed & Subjective & Yes & No & $6 / 8$ \\
\hline Christian et al. [29] & $\begin{array}{l}\text { CA, US/ } \\
2006\end{array}$ & No & $\begin{array}{l}\text { SOFAa, NYHA } \\
\text { Classification; } \\
\text { Child-Pugh }\end{array}$ & Adult & $48 h^{b}$ e $120 h$ & Objectives & No & Yes & $8 / 9$ \\
\hline Hick \& O’Laughlin [18] & US/2006 & No & SOFA & Adult/pediatric & Uninformed & Objectives & No & Yes & $9 / 9$ \\
\hline Devereaux et al. [30] & US/2008 & No & SOFA & Adult/pediatric & Daily & Objectives & Yes & Yes & $9 / 9$ \\
\hline Powell, Christ, Birkhead [19] & US/2008 & Yes & $\begin{array}{l}\text { SOFA, MELD, } \\
\text { NYHA Classification }\end{array}$ & Adult & $48 \mathrm{~h}$ e $120 \mathrm{~h}$ & Objectives & No & Yes & $8 / 9$ \\
\hline Lin \& Anderson-Shaw [20] & US/2009 & No & $\begin{array}{l}\text { SOFA'; MELD; } \\
\text { NYHA Classification }\end{array}$ & Adult & $48 \mathrm{~h}$ e $120 \mathrm{~h}$ & Objectives & No & Yes & $8 / 9$ \\
\hline Frolic, Kata, Kraus [21] & $C A / 2009$ & No & $\begin{array}{l}\text { SOFA; ISS; NYHA } \\
\text { Classification; } \\
\text { Child-Pugh }\end{array}$ & Adult & $48 \mathrm{~h}$ e $120 \mathrm{~h}$ & Objectives & Yes & Yes & $9 / 9$ \\
\hline White et al. [22] & US/2009 & No & SOFA & Adult & Uninformed & Objectives & Yes & Yes & $8 / 9$ \\
\hline Christian et al. [23] & $\begin{array}{l}\text { CA, CN, US, } \\
\text { UK,IL/2010 }\end{array}$ & No & $\begin{array}{l}\text { SOFA', NYHA } \\
\text { Classification; } \\
\text { Child-Pugh; TRISS }\end{array}$ & Adult & $48 \mathrm{~h}$ e $120 \mathrm{~h}$ & Objectives & No & Yes & $8 / 9$ \\
\hline Christian et al. [31] & $\begin{array}{l}\text { CA, IL, US, } \\
\text { CN/2014 }\end{array}$ & No & $\begin{array}{l}\text { SOFA, MELD; } \\
\text { NYHA Classification }\end{array}$ & Adult/pediatric & $\begin{array}{l}72 \mathrm{~h} \text { and } 96 \mathrm{~h} \\
\text { or as needed }\end{array}$ & Objectives & Yes & Yes & $9 / 9$ \\
\hline Gall et al. [24] & US/2016 & No & POD; DV & Pediatric & Uninformed & Objectives & No & No & $6 / 9$ \\
\hline $\begin{array}{l}\text { Daugherty Biddison } \\
\text { et al. [32] }\end{array}$ & US/2019 & Yes & $\begin{array}{l}\text { SOFA; PELOD-2; } \\
\text { NYHA Classification; } \\
\text { Child-Pugh }\end{array}$ & Adult/pediatric & $24 h, 48 h$ e $120 h$ & Objectives & Yes & Yes & $9 / 9$ \\
\hline Rubio et al. [25] & $\mathrm{ES} / 2020$ & No & $\begin{array}{l}\text { SOFA, Charlson } \\
\text { Comorbidity Index } \\
\text { (CCI), NECPAL }\end{array}$ & Adult/pediatric & Daily & Objectives & No & Yes & $8 / 9$ \\
\hline White \& Lo [26] & US/2020 & No & $\begin{array}{l}\text { SOFA; LAPS2; MELD; } \\
\text { NYHA Classification; } \\
\text { ECl; COPS2 }\end{array}$ & $\begin{array}{l}\text { Adult/pediatric } \\
\text { (from } 12 \text { years) }\end{array}$ & Daily & Objectives & Yes & Yes & $9 / 9$ \\
\hline $\begin{array}{l}\text { Swiss Academy Of } \\
\text { Medical Sciences [27] }\end{array}$ & $\mathrm{CH} / 2020$ & No & $\begin{array}{l}\text { NYHA Classification; } \\
\text { Child-Pugh; KDIGO }\end{array}$ & Adult & $48 \mathrm{~h}$ & Objectives & No & Yes & $5 / 9$ \\
\hline
\end{tabular}

Note: Country: NZ New Zealand, CH Switzerland, ES Spain, CN China, UK United Kingdom, IL Israel, CA Canada, US United State of America

Clinical instrument: SOFA Sequential Organ Failure Assessment, PELOD2 Pediatric Logistic Organ Dysfunction 2, LAPS2 Laboratory-Based Acute Physiology Score, MELD Model for End-Stage Liver Disease, NECPAL Palliative Needs, NYHA Classification New York Heart Association Classification, ISS Injury Severity Score, TRISS Trauma and Injury Severity Score, KDIGO Kidney Disease Improving Global Outcomes, ECI Elixhauser Comorbidity Index, COPS2 Comorbidity Point Score, POD Probability of Death, DV Days on Mechanical Ventilation (DV) SOFA $^{\mathrm{a}}=$ Adapted SOFA; $\mathrm{h}^{\mathrm{b}}=$ hours; $\mathbf{U}^{\mathrm{c}}=$ Usability

be useful for screening decisions in the COVID-19 pandemic [33].

One study [33] suggests that these instruments should not use a single scoring tool but rather a combination of scoring systems and mortality predictors in intensive care, such as disease-specific indicators for non-COVID19 conditions, frailty score, comorbidity rates, and clinical judgment [33].

PELOD-2 was developed and validated to assess the severity of pediatric multiple organ dysfunction syndrome cases [46], based on the PELOD created in 1999 [47] and validated in pandemic settings [48]. The PELOD-2 score, different from its original version, includes mean arterial pressure and lactatemia in cardiovascular dysfunction and does not include liver dysfunction [46]. Among its limitations, the need for laboratory tests for evaluation has been highlighted [32, 49]. In this area, the Pediatric Emergency Task Force for Critical Mass Care developed specific recommendations for the organization, screening, and treatment in scenarios that require the management of scarce resources [50].

It is noteworthy that, currently, it is unclear whether any severity score for pediatric or neonatal disease provides valid prognostic measures for COVID-19 patients [51].

The screening structure can combine several evaluation parameters specific for diseases or health conditions, which generally integrate the inclusion and exclusion criteria. This screening should be based on clear and accurate evidence to avoid arbitrary admissions and prevent the prolonged treatment of patients whose survival is unlikely [52].

The inclusion criteria must be objective [18-27, 29-32] and facilitate the suitable and rapid referral of potential survivors during pandemics or major disasters [53]. Exclusion criteria should identify patients who are unlikely to obtain benefits through intensive care [53], as recommended by the European Society of Intensive Care Medicine task force $[23,54]$. 
Table 2 Examples of the application of criteria found in the screening instruments in the allocation of mechanical ventilators

\begin{tabular}{|c|c|c|c|c|}
\hline Section & $\begin{array}{l}\text { Ethical } \\
\text { values }\end{array}$ & $\begin{array}{l}\text { Criteria found in the } \\
\text { instruments }\end{array}$ & History & Commented examples \\
\hline \multirow[t]{2}{*}{$\begin{array}{l}\text { Clinical } \\
\text { criteria }\end{array}$} & $\begin{array}{l}\text { "Save } \\
\text { more } \\
\text { lives" }\end{array}$ & $\begin{array}{l}\text { Instruments with exclusion } \\
{[18-21,23,25,27,29-32]}\end{array}$ & $\begin{array}{l}\text { Patient A: } 26 \text { years old, affected by severe } \\
\text { trauma, with respiratory failure. } \\
\text { Patient B: } 65 \text { years old, without comorbidities, } \\
\text { diagnosed with COVID- } 19 \text { and with respiratory } \\
\text { failure. }\end{array}$ & $\begin{array}{l}\text { The resource would be allocated to patient } \\
B \text { as a result of patient A's poor prognosis } \\
\text { and the high probability of death. Severe } \\
\text { trauma is an exclusion criterion in most } \\
\text { instruments. }\end{array}$ \\
\hline & $\begin{array}{l}\text { "Save } \\
\text { more } \\
\text { lives" }\end{array}$ & $\begin{array}{l}\text { Instruments without } \\
\text { exclusion (multiple } \\
\text { principles) }[22,26]\end{array}$ & $\begin{array}{l}\text { Patient A: } 49 \text { years old with mild COPD, } \\
\text { benzodiazepine intoxication and respiratory } \\
\text { failure, SOFA score: } 4 \text {. } \\
\text { Patient B: } 61 \text { years old, with severe Alzheimer's } \\
\text { disease, chronic renal failure and on dialysis, } \\
\text { and diagnosis of COVID-19 with respiratory } \\
\text { failure, SOFA score: } 10 \text {. } \\
\text { Patient C: } 64 \text { years old, without comorbidities, } \\
\text { with } 60 \% \text { of the body area injured by } 2 \text { nd and } \\
\text { 3rd degree burns, with sepsis, multiple organ } \\
\text { failure and respiratory failure, SOFA score: } 12: 12 \text {. }\end{array}$ & $\begin{array}{l}\text { The resource would be given to Patient } A \text {, } \\
\text { to the detriment of Patients } B \text { and } C \text {, who } \\
\text { had lower prioritization due to the short } \\
\text { and long term prognosis and life cycle. } \\
\text { Despite health conditions and severe } \\
\text { comorbidities, all patients are included } \\
\text { in the screening protocol. }\end{array}$ \\
\hline $\begin{array}{l}\text { Non- } \\
\text { clinical } \\
\text { criteria }\end{array}$ & "Equity" & Life cycle [21] & $\begin{array}{l}\text { Patient A: } 75 \text { years old. No comorbidities, } \\
\text { diagnosis of COVID-19 with respiratory failure. } \\
\text { SOFA: } 6 \text {. } \\
\text { Patient B: } 45 \text { years old. No comorbidities, } \\
\text { diagnosed with COVID-19 and respiratory } \\
\text { failure, SOFA: } 6 \text {. }\end{array}$ & $\begin{array}{l}\text { Patient B would have a higher priority } \\
\text { to receive the resource, based on the } \\
\text { logic that everyone should have the } \\
\text { same opportunity to live all the cycles } \\
\text { of life. }\end{array}$ \\
\hline $\begin{array}{l}\text { Tiebreaker } \\
\text { criteria }\end{array}$ & "Equality" & Ballot $[17,21,22,26,31,32]$ & $\begin{array}{l}\text { Patient A: } 20 \text { years old, without severe } \\
\text { comorbidities, diagnosed with COVID-19 } \\
\text { with respiratory failure, SOFA score } 7 . \\
\text { Patient B: } 39 \text { years old, diagnosed with } \\
\text { COVID-19 with respiratory failure, without } \\
\text { severe comorbidities. SOFA } 7 \text {. }\end{array}$ & $\begin{array}{l}\text { Patients had the same priority score, both } \\
\text { in terms of prognosis and life cycle } \\
\text { ( } 0-49 \text { years). The resource would be } \\
\text { allocated based on chance, in a fair } \\
\text { and transparent way. }\end{array}$ \\
\hline
\end{tabular}

Note: SOFA Sequential Organ Failure Assessment, COPD chronic obstructive pulmonary disease

In general, studies indicate the following inclusion criteria: respiratory failure $[18-21,23,25,27,29-31]$ and hypotension [21, 23, 27, 29-31].

The most common exclusion criteria were pulmonary impairment [41], trauma (Injury Severity Score [21]; Trauma and Injury Severity Score [23]), renal dysfunction (Kidney Disease Improving Global Outcomes [27]), hepatic (Model for End-Stage Liver Disease [19, 20, 26, 31]; Child-Pugh classification [21, 23, 27, 29, 32]) and cardiac classification (New York Heart Association classification [19-21, 23, 26, 27, 29, 31, 32]), and comorbidities (Charlson comorbidity index [25]; Elixhauser Comorbidity Index [26]; Comorbidity Point Score 2 [26]). In addition, there are studies $[22,26]$ that use some of these criteria in order to prioritize patients.

In order to mitigate prolonged treatments and maximize the chance of benefit, it is recommended that patients should be continuously reassessed as this allows for the confirmation of clinical evolution and opens the possibility of the redistribution of the mechanical ventilator to patients who would have a better survival prognosis [35]. Some studies mention that this reassessment must be carried out daily [25, 26, 30], and others indicate different times: intervals of 24, 48, and $120 \mathrm{~h} \mathrm{[32];} 48$ and $120 \mathrm{~h}$ [19-21, 23, 29]; and 72 and $96 \mathrm{~h}$ [31].

\section{Non-clinical criteria}

In COVID-19 patients, the advanced age of the patients suggests a higher mortality rate [14, 43, 55]. This factor seems to be important in the utilitarian approach but should not be the only criterion to determine screening decisions [56, 57].

The use of age $[21,25,27,29,30,32]$ as a non-clinical criterion has been strongly contested for violating the notions of equality and justice $[58,59]$. Even so, there are authors who defend the use of age only as a tiebreaker criterion [59] and others who refute even that use, as they consider that a criterion is seen as discriminatory and cannot suddenly become ethically appropriate [60].

This criterion seems to be associated with the idea of frailty [61] and chronic comorbidities [62], suggesting that increasing age leads to a higher probability of death [47]. Replacing the age criterion with the frailty assessment seems to better determine the risk of worse health outcomes and avoids age discrimination in the screening protocols [63]. On the other hand, carrying out assessments based on frailty to determine the probability of survival may constitute indirect discrimination as the elderly and people with specific disabilities may be considered more fragile [64]. 
The use of the life cycle [21] maintains that everyone should have the same opportunity to live all the cycles of life. Resources must then be distributed to ensure that those who have not yet lived this life are given priority to those who have already managed to do so [65]. The fair inning argument puts young people at an advantage over old people in the context of healthcare decisionmaking-a view that generally receives implicit public approval based on an efficiency perspective since younger people are more able to gain years of their life, which makes any other choice difficult to justify in social and ethical terms [66].

Pregnancy [32] is a unique state in which clinical decisions directly affect the state of health and the expectation of survival not only for the mother, but also for the fetus inside her [32]. These women represent a particular population, which historically has been disproportionately affected in seasonal outbreaks and in the influenza pandemic $[67,68]$. A recent forecast suggests that COVID-19 will affect millions of women in the USA in the hospital when they are giving birth [69]. One study states that prioritization should be based on the criterion of viable pregnancy [67] and another on pregnancy as long as the fetus is healthy [32]. This study also highlights that there is a possibility that pregnant women with comorbidities are given a lower priority [67].

The net benefit [17] criterion assesses the difference between the estimated benefit of accessing the resource and the harm caused by not accessing it [17]. The instrumental value [21] considers professionals, among whom are health professionals, vaccine researchers, public health professionals, and others essential to deal with a disaster scenario [21, 27]. This effect is supported by the utilitarian principle of triage as it prioritizes access to the resources for people with essential skills and knowledge to save others' lives (assuming the recovery of the multiplier to exercise their knowledge), thus multiplying the net benefit to society [21, 70].

Having someone dependent on care [21] is considered a criterion in the triage model as it is considered that this criterion should be prioritized due to the fact that less harm will be caused to families and society [21]. The existence of ADLW [27] should be verified as people are more aware of the importance of preparing this document, as well as having conversations with their families about the adoption of measures at the end of life [71]. The option of not using IMV, painful or exhausting treatment, or even the wish to not resuscitate in case of cardiac arrest shortens the triage process, facilitates decision making, and directs the patient's referral to palliative care.

It is important to emphasize that the screening instruments must take into account human rights in terms of the set of protections and rights offered to all people
[59]. The fundamental principles of dignity, nondiscrimination, equal opportunities, and accessibility should be major factors when planning the allocation of scarce resources [72]. In this sense, ventilators should not be allocated on the basis of morally irrelevant aspects such as sex, race, religion, financial condition, social relations, citizenship, and physical or intellectual disabilities [26, 73]. It should be emphasized, therefore, that these people should not suffer any type of discrimination due to their condition and should be included in the screening protocols [59].

\section{Tiebreaker criteria}

After applying the specific decision-making criteria, there may be a tie in prioritizing the resource. In order to solve this problem, the instruments suggest that the tiebreaker takes into account the following criteria: life cycle $[26,32]$, instrumental value [26], gross prioritization score [17, 30-32], order of arrival, and ballot $[17,21,22,26,31,32]$.

In some studies, the life cycle $[26,32]$ and instrumental value [26] were considered as tiebreaker criteria; however, they can also be used, as previously mentioned, in the application of criteria which are supplementary to clinical criteria.

Instrumental value [26] does not judge people by their value but rather by their utilitarian basis [74]. The application of this criterion in the tiebreaker encounters obstacles when the people evaluated have the same utilitarian value.

The criterion of the gross prioritization score [26] was listed as a tiebreaker criterion in a study that uses a system of multiple principles, in which it considers the lowest gross value of this score in the tiebreaker.

Order of arrival, "first come, first served" is mentioned as a tiebreaker criterion by some authors [17, 30-32]. However, there are studies that state that this criterion is not fair as those with greater social resources will have quicker access than those who have little access to health care [75-77].

The ballot $[17,21,22,26,31,32]$ is a tiebreaker criterion considered transparent and impartial in random selection [21] and also seen as a fair way to ensure that all patients have equal access to life-saving care [74]. This criterion requires little knowledge of the recipients, can be applied quickly, and resists corruption. On the other hand, ballots-and the egalitarian principles of justice in general-are insensitive to factors that are also intuitively important to many, such as the needs of patients and the likelihood of obtaining benefits from the treatment $[75,76]$.

The tiebreaker criteria identified in the analyzed instruments are varied, have strong points, disadvantages, and show a lack of consensus. 


\section{Ethical aspects}

In health, one of the ethical dilemmas that emerges is who to give priority to in order to receive assistance/resources $[14,41]$. In general, public health measures often adopt a utilitarian orientation that has social utility as a fundamental principle. This principle states that actions are ethically correct when they tend to promote the greatest amount of pleasure (happiness, well-being) of all those whose interests are at stake [78].

Life is a social value [79]. Thus, in the face of a catastrophic situation such as that of a pandemic, the main aim of a society will be to make every effort to use all its resources not only to "save lives," but to save "the greatest possible number of lives." This scenario becomes complex in situations of the scarcity of resources because criteria, and choices will inevitably have to be made about who will and who will not have access to them. In this sense, distributive justice, which guides the utilitarian paradigm of "the greatest good for the greatest number of people" emerges as a principle for decision making, as evidenced in the guidelines specified in several studies [17-23, 25-27, 29, 31, 32].

A number of studies [18-23, 26, 27, 29, 31, 32] based on this paradigm developed instruments with clinical criteria based on the probability of the survival of people who need the resource and/or the identification of comorbidities, considering that those in better health will have greater chances of life and a possible rapid response to the use of the resource, thus freeing it to be used for other people. However, it is important that the screening instruments merge clinical and ethical criteria to create a balanced evaluation process [22].

Although the application of criteria based on the utilitarian approach is more frequent, it is also possible to identify in the instruments $[17,21,22,26,31,32]$ criteria based on the egalitarian approach that argues that all people have incomparable value. From this perspective, no one has more or less value than anyone else, and neither does this value increase or decrease based on their quality of life related to health, personal satisfaction or well-being, intelligence, talent, or instrumental value [80]. Egalitarianism is based only on the consideration of need and rejects the consideration of the probability of survival, longevity, or quality of life typical of the utilitarian approach [64].

The utilitarian and egalitarian approaches can both be seen as inconsistent and unjustified [64], and therefore, seeking a balance between equality and utility may be the way to build a new ethical structure to allocate scarce resources [64].

In general, a screening system is built in order to meet the values of human life, health, an efficient use of resources, and justice [79]. Even so, it is possible to find triage instruments in the allocation of different scarce resources that present discriminatory criteria [81]. From an ethical point of view, the exclusion of patients with comorbidities that do not influence their probability of survival is questionable and should not be considered [82].

Some of the studies analyzed considered or associated with clinical criteria, values based on the principle of equity-specifically based on the life cycle, explained by the guideline "maximize the chances of individuals to live each stage of life" [22, 25]; those based on the principle of reciprocity that values those who demonstrate altruism taking care of others at the expense of their own safety during a pandemic $[17,21]$; those based on the principle of proportionality, that is, those with a better prognosis will have easier access to resources [25]; and those based on the principle of autonomy [83] aimed at those who expressed their choice in the ADLW [27].

It is important to consider that the existence of instruments built from literature reviews and expert consensus, but without popular participation to validate the guidelines, may not represent the real values of the society in question. There is no doubt that the public may have a limited understanding and, consequently, less possibility of contributing in terms of the pertinence and application of the clinical criteria of the specialized medical domain, which can be seen in the instruments; however, society can greatly collaborate in the discussion, reflection, and definition of "non-clinical" criteria as these clearly involve "social values."

Few instruments have been developed with the participation of the public $[19,32]$. This fact attracts attention since it is only through the collective construction of these guidelines and public policies that it is possible to minimize the paternalistic bias present in the construction of the instruments developed for this purpose. Society can take part directly or through elected representatives, and public opinion surveys can also guide the construction of instruments aimed at allocating scarce resources [84].

Transparency and social inclusion are essential conditions in the process of building any ethical structure for decision making in situations of scarce resources because it is of paramount importance that citizens trust health institutions and the provision of care in the system of which they are part [85].

Some of the instruments [18-23, 25-27, 29-32] evaluated addressed the notion of removing invasive mechanical ventilators from patients initially screened with a higher probability of mortality in order to benefit patients with a high probability of survival. This proposal aims at the optimization of resources, and although it can ethically be defended from the utilitarian point of view, it places the health professional in a disturbing 
situation and is therefore difficult to implement. It should be noted that these instruments rarely provide clinical or ethical guidance on how these decisions should be applied in practice, discussed with family members, and whether they meet legal standards [86-89].

It is positive that some guidelines have highlighted the duty to care for those who do not meet the criteria for using scarce resources through actions based on comfort and pain relief (palliative care) [17, 19, 20, 23, 29, 30]. On the other hand, there is a considerable lack of clarity regarding the values and ethical principles on which these instruments are based as they are presented disconnectedly in the body of the articles and are often not linked to the criteria and actions established in the guidelines.

It should be emphasized that an ethical problem always presents a conflict of values, duties, or principles, and therefore, in situations of ethical conflict, decisions cannot be said to be "right" or "wrong." What is necessary is that they are all reasonable and that the reasons in their favor can be understood so the decisions taken must be prudent [90].

\section{Implications for practice}

The instruments identified for allocating invasive mechanical ventilators have different structures and criteria, which make their reproducibility limited as the local context must be considered. In order to help the construction of screening protocols for the allocation of invasive mechanical ventilators, we have summarized the review and suggested a number of items to consider (Table 3).

\section{Conclusion}

Decision making in allocating ventilators is a complex practice, especially in pandemic settings. For this purpose, there are instruments with varying criteria, which address this difficult and controversial topic.

A number of these instruments have poor scientific evidence and until now have not included the participation of the public or have not yet been submitted to validation by society, which is the affected population and is thus interested in the context. Therefore, certain established criteria may not represent social values and may even be discriminatory.

We believe that it is important to prepare comprehensive public policies for all health services in advance and consider preventive actions to halt the spread of the disease in pandemic scenarios, as well as measures to allocate scarce resources that include clear, objective, and transparent screening instruments which are easy to use in order to avoid dubious interpretations and mistakes regarding the application of the established criteria. Finally, the elaboration of these guidelines cannot be
Table 3 Items to be considered in the construction of the screening protocol

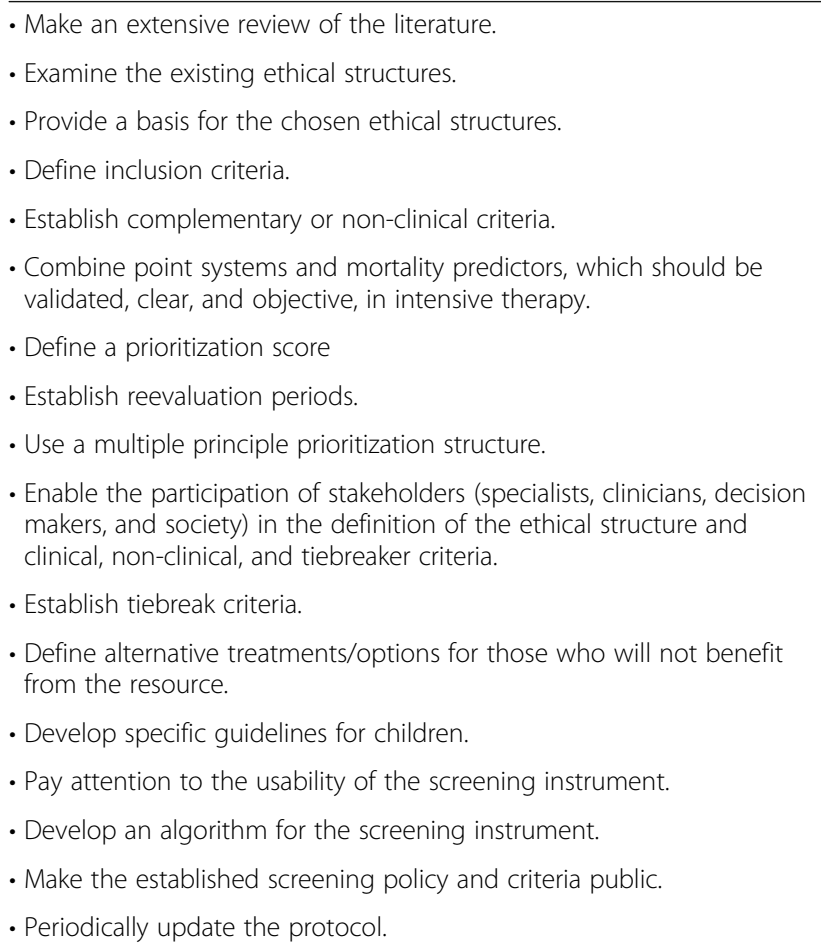

restricted to specialists as this question involves ethical considerations which make the participation of the population necessary.

\section{Supplementary information}

Supplementary information accompanies this paper at https://doi.org/10. 1186/s13054-020-03298-3.

Additional file 1. Search terms and strategies

Additional file 2. Summaries of the instruments presented in the article.

\begin{abstract}
Abbreviations
ADLW: Advance directives and living will; LAPS2: Laboratory acute physiology; PELOD-2: Pediatric logistic organ dysfunction 2; SARS: Severe respiratory distress syndrome; SOFA: Sequential Organ Failure Assessment
\end{abstract}

\section{Acknowledgements}

The authors would like to thank the librarian Juliana Akie Takahashi for her support in the bibliographical research.

\section{Authors' contributions}

The authors read and approved the final manuscript.

\section{Funding}

Not applicable.

Availability of data and materials

All data analyzed during this study are included in this published article [and a supplementary information file].

Ethics approval and consent to participate Not applicable. 


\section{Consent for publication}

Not applicable.

\section{Competing interests}

The authors declare that they have no competing interests.

Received: 16 June 2020 Accepted: 17 September 2020

Published online: 29 September 2020

\section{References}

1. Zhu N, Zhang D, Wang W, et al. A novel coronavirus from patients with pneumonia in China, 2019. N Engl J Med. 2020;382(8):727-33. https://doi. org/10.1056/NEJMoa2001017

2. Chen $N$, Zhou M, Dong $X$, et al. Epidemiological and clinical characteristics of 99 cases of 2019 novel coronavirus pneumonia in Wuhan, China: a descriptive study. Lancet. 2020;395(10223):507-13. https://doi.org/10.1016/ S0140-6736(20)30211-7.

3. Mehta P, McAuley DF, Brown M, et al. COVID-19: consider cytokine storm syndromes and immunosuppression. Lancet. 2020;395(10229):1033-4. https://doi.org/10.1016/S0140-6736(20)30628-0.

4. World Health Organization. Novel coronavirus (2019-nCoV) situation report - 10. January 30, 2020. https://www.who.int/docs/default-source/ coronaviruse/situation-reports/20200130-sitrep-10-ncov.pdf?sfvrsn=d0b2e4 80_2. Accessed 16 Aug 2020.

5. Halpern SD, Truog RD, Miller FG. Cognitive bias and public health policy during the COVID-19 pandemic. JAMA. 2020. https://doi.org/10.1001/jama. 2020.11623.

6. The Lancet. COVID-19 in Brazil: "so what?". Lancet. 2020;395(10235):1461. https://doi.org/10.1016/S0140-6736(20)31095-3

7. Potere N, Valeriani E, Candeloro M, et al. Acute complications and mortality in hospitalized patients with coronavirus disease 2019: a systematic review and meta-analysis. Crit Care. 2020;24(1):389. https://doi.org/10.1186/s13054020-03022-1.

8. Docherty AB, Harrison EM, Green CA, et al. Features of 20133 UK patients in hospital with covid-19 using the ISARIC WHO clinical characterisation protocol: prospective observational cohort study. BMJ. 2020;369:m1985. https://doi.org/10.1136/bmj.m1985.

9. Grant MC, Geoghegan L, Arbyn M, et al. The prevalence of symptoms in 24,410 adults infected by the novel coronavirus (SARS-CoV-2; COVID-19): a systematic review and meta-analysis of 148 studies from 9 countries. PLoS One. 2020;15(6):e0234765. https://doi.org/10.1371/journal.pone.0234765.

10. Holanda MA, Pinheiro BV. COVID-19 pandemic and mechanical ventilation: facing the present, designing the future. J Bras Pneumol. 2020;46(4): e20200282. https://doi.org/10.36416/1806-3756/e20200282.

11. Ventilator stockpiling and availability in the US. Baltimore: Johns Hopkins Bloomberg School of Public Health, Center for Health Security, July 1, 2020. https://www.centerforhealthsecurity.org/resources/COVID-19/COVID-19-factsheets/200214-VentilatorAvailability-factsheet.pdf. Accessed 16 Aug 2020

12. United States resource availability for COVID-19. Society of Critical Care Medicine, May 12, 2020. https://www.sccm.org/Blog/March-2020/UnitedStates-Resource-Availability-for-COVID-19. Accessed 16 Aug 2020.

13. Jones F. Respiradores vitais. Revista de pesquisa Fapesp, April 08, 2020 https://revistapesquisa.fapesp.br/respiradores-vitais/. Accessed 16 Aug 2020.

14. Rosenbaum L. Facing COVID-19 in Italy - ethics, logistics, and therapeutics on the epidemic's front line. N Engl J Med. 2020;382(20):1873-5. https://doi. org/10.1056/NEJMp2005492.

15. King MA, Kissoon N. Triage during pandemics: difficult choices when business as usual is not an ethically defensible option. Crit Care Med. 2016 44(9):1793-5. https://doi.org/10.1097/CCM.0000000000001796.

16. Pauls MA, Migneault D, Bakewell F. Ethical considerations in the allocation of critical care resources when capacity is overwhelmed. CJEM. 2020;22(4): 404-6. https://doi.org/10.1017/cem.2020.354.

17. Ardagh M. Criteria for prioritising access to healthcare resources in New Zealand during an influenza pandemic or at other times of overwhelming demand. N Z Med J. 2006;119(1243):U2256.

18. Hick JL, O'Laughlin DT. Concept of operations for triage of mechanical ventilation in an epidemic. Acad Emerg Med. 2006;13(2):223-9. https://doi. org/10.1197/j.aem.2005.07.037.

19. Powell T, Christ KC, Birkhead GS. Allocation of ventilators in a public health disaster. Disaster Med Public Health Prep. 2008;2(1):20-6. https://doi.org/10. 1097/DMP.0b013e3181620794.
20. Lin JY, Anderson-Shaw L. Rationing of resources: ethical issues in disasters and epidemic situations. Prehosp Disaster Med. 2009;24(3):215-21. https:// doi.org/10.1017/s1049023x0000683x.

21. Frolic A, Kata A, Kraus P. Development of a critical care triage protocol for pandemic influenza: integrating ethics, evidence and effectiveness. Healthc Q. 2009;12(4):54-62. https://doi.org/10.12927/hcq.2009.21054.

22. White DB, Katz MH, Luce JM, Lo B. Who should receive life support during a public health emergency? Using ethical principles to improve allocation decisions. Ann Intern Med. 2009;150(2):132-8. https://doi.org/10.7326/00034819-150-2-200901200-00011.

23. Christian MD, Joynt GM, Hick JL, Colvin J, Danis M, Sprung CL. Chapter 7. Critical care triage. Recommendations and standard operating procedures for intensive care unit and hospital preparations for an influenza epidemic or mass disaster. Intensive Care Med. 2010;36(Suppl 1):S55-64. https://doi. org/10.1007/s00134-010-1765-0.

24. Gall C, Wetzel R, Kolker A, Kanter RK, Toltzis P. Pediatric triage in a severe pandemic: maximizing survival by establishing triage thresholds. Crit Care Med. 2016;44(9):1762-8. https://doi.org/10.1097/CCM.0000000000001759.

25. Rubio O, Estella A, Cabre L, et al. Recomendaciones éticas para la toma de decisiones difíciles en las unidades de cuidados intensivos ante la situación excepcional de crisis por la pandemia por covid-19: revisión rápida y consenso de expertos. Med Intensiva. 2020;S0210-5691(20):30110-8. https:// doi.org/10.1016/j.medin.2020.04.006.

26. White $D B$, Lo B. A framework for rationing ventilators and critical care beds during the COVID-19 pandemic. JAMA. 2020. https://doi.org/10.1001/jama. 2020.5046.

27. Swiss Academy Of Medical Sciences. COVID-19 pandemic: triage for intensive-care treatment under resource scarcity. Swiss Med Wkly. 2020;150: w20229. https://doi.org/10.4414/smw.2020.20229.

28. Christian MD, Poutanen SM, Loutfy MR, Muller MP, Low DE. Severe acute respiratory syndrome. Clin Infect Dis. 2004;38(10):1420-7. https://doi.org/10. 1086/420743.

29. Christian MD, Hawryluck L, Wax RS, et al. Development of a triage protocol for critical care during an influenza pandemic. CMAJ. 2006;175(11):1377-81. https://doi.org/10.1503/cmaj.060911.

30. Devereaux AV, Dichter JR, Christian MD, et al. Definitive care for the critically ill during a disaster: a framework for allocation of scarce resources in mass critical care: from a Task Force for Mass Critical Care summit meeting, January 26-27, 2007, Chicago, IL. Chest. 2008;133(Suppl 5):51S-66S. https:// doi.org/10.1378/chest.07-2693.

31. Christian MD, Sprung CL, King MA, et al. Triage: care of the critically ill and injured during pandemics and disasters: CHEST consensus statement. Chest. 2014;146(Suppl 4):e61S-74S. https://doi.org/10.1378/chest.14-0736.

32. Daugherty Biddison EL, Faden R, Gwon HS, et al. Too many patients ... a framework to guide statewide allocation of scarce mechanical ventilation during disasters. Chest. 2019;155(4):848-54. https://doi.org/10.1016/j.chest. 2018.09.025.

33. Maves RC, Downar J, Dichter JR, et al. Triage of scarce critical care resources in COVID-19 an implementation guide for regional allocation: an expert panel report of the task force for mass critical care and the American College of Chest Physicians. Chest. 2020;158(1):212-25. https://doi.org/10. 1016/j.chest.2020.03.063.

34. Ornelas J, Dichter JR, Devereaux AV, et al. Methodology: care of the critically ill and injured during pandemics and disasters: CHEST consensus statement. Chest. 2014;146(Suppl 4):35S-41S. https://doi.org/10.1378/chest.14-0746.

35. Cupp OS, Predmore BG. Planning for the next influenza pandemic: using the science and art of logistics. Am J Disaster Med. 2011;6(4):243-54. https:// doi.org/10.5055/ajdm.2011.0063.

36. Morata L. An evolutionary concept analysis of futility in health care. J Adv Nurs. 2018;74(6):1289-300. https://doi.org/10.1111/jan.13526.

37. Meadow W, Pohlman A, Frain L, et al. Power and limitations of daily prognostications of death in the medical intensive care unit. Crit Care Med. 2011;39(3):474-9. https://doi.org/10.1097/CCM.0b013e318205.

38. Meadow W, Pohlman A, Reynolds D, et al. Power and limitations of daily prognostications of death in the medical ICU for outcomes in the following 6 months. Crit Care Med. 2014;42(11):2387-92. https://doi.org/10.1097/CCM. 0000000000000521

39. Soliman IW, Cremer OL, de Lange DW, et al. The ability of intensive care unit physicians to estimate long-term prognosis in survivors of critical illness. J Crit Care. 2018:43:148-55. https://doi.org/10.1016/j.jcrc. 2017.09.007. 
40. Hallen SA, Hootsmans NA, Blaisdell L, Gutheil CM, Han PK. Physicians' perceptions of the value of prognostic models: the benefits and risks of prognostic confidence. Health Expect. 2015;18(6):2266-77. https://doi.org/10. 1111/hex.12196.

41. Christian MD. Triage. Crit Care Clin. 2019;35(4):575-89. https://doi.org/10. 1016/j.ccc.2019.06.009.

42. Aziz S, Arabi YM, Alhazzani W, et al. Managing ICU surge during the COVID19 crisis: rapid guidelines. Intensive Care Med. 2020;46:1303-25. https://doi. org/10.1007/s00134-020-06092-5.

43. Yang $X, Y u Y, X u$ J, et al. Clinical course and outcomes of critically ill patients with SARS-CoV-2 pneumonia in Wuhan, China: a single-centered, retrospective, observational study. Lancet Respir Med. 2020;8(5):475-81. https://doi.org/10.1016/S2213-2600(20)30079-5.

44. Liu Y, Sun W, Li J, Chen L, et al. Clinical features and progression of acute respiratory distress syndrome in coronavirus disease 2019. medRxiv. 2020. https://doi.org/10.1101/2020.02.17.20024166

45. Zhang G, Hu C, Luo L, et al. Clinical features and short-term outcomes of 221 patients with COVID-19 in Wuhan, China. J Clin Virol. 2020;127:104364. https://doi.org/10.1016/j.jcv.2020.104364.

46. Leteurtre S, Duhamel A, Salleron J, et al. PELOD-2: an update of the PEdiatric logistic organ dysfunction score. Crit Care Med. 2013;41(7):176173. https://doi.org/10.1097/CCM.0b013e31828a2bbd.

47. Leteurtre S, Duhamel A, Grandbastien B, Lacroix J, Leclerc F. Paediatric logistic organ dysfunction (PELOD) score. Lancet. 2006;367(9514):897-902. https://doi.org/10.1016/S0140-6736(06)68371-2.

48. Kim KM, Cinti S, Gay S, Goold S, Barnosky A, Lozon M. Triage of mechanical ventilation for pediatric patients during a pandemic. Disaster Med Public Health Prep. 2012;6(2):131-7. https://doi.org/10.1001/dmp.2012.19.

49. Horvat CM, Ogoe H, Kantawala S, et al. Development and performance of electronic pediatric risk of mortality and pediatric logistic organ dysfunction-2 automated acuity scores. Pediatr Crit Care Med. 2019;20(8): e372-9. https://doi.org/10.1097/PCC.0000000000001998.

50. Christian MD, Toltzis P, Kanter RK, et al. Treatment and triage recommendations for pediatric emergency mass critical care. Pediatr Crit Care Med. 2011;12(Suppl 6):S109-19. https://doi.org/10.1097/PCC. Ob013e318234a656.

51. Laventhal N, Basak R, Dell ML, et al. The ethics of creating a resource allocation strategy during the COVID-19 pandemic. Pediatrics. 2020;146(1): e20201243. https://doi.org/10.1542/peds.2020-1243.

52. Mielke J, Martin DK, Singer PA. Priority setting in a hospital critical care unit: qualitative case study. Crit Care Med. 2003;31(12):2764-8. https://doi.org/10. 1097/01.CCM.0000098440.74735.DE.

53. Khan Z, Hulme J, Sherwood N. An assessment of the validity of SOFA score based triage in $\mathrm{H} 1 \mathrm{~N} 1$ critically ill patients during an influenza pandemic. Anaesthesia. 2009;64(12):1283-8. https://doi.org/10.1111/j.1365-2044.2009. 06135.x.

54. White ST, Cardenas YR, Nates JL. What every intensivist should know about intensive care unit admission criteria. Rev Bras Ter Intensiva. 2017;29(4):4147. https://doi.org/10.5935/0103-507X.20170073.

55. Gupta S, Hayek SS, Wang W, et al. Factors associated with death in critically III patients with coronavirus disease 2019 in the US. JAMA Intern Med. 2020: e203596. https://doi.org/10.1001/jamainternmed.2020.3596.

56. Sprung $\mathrm{CL}$, Joynt GM, Christian MD, Truog RD, Rello J, Nates JL. Adult ICU triage during the coronavirus disease 2019 pandemic: who will live and who will die? Recommendations to improve survival. Crit Care Med. 2020; 48(8):1196-202. https://doi.org/10.1097/CCM.0000000000004410.

57. Haas LEM, de Lange DW, van Dijk D, van Delden JJM. Should we deny ICU admission to the elderly? Ethical considerations in times of COVID-19. Crit Care. 2020;24(1):321. https://doi.org/10.1186/s13054-020-03050-x.

58. Castro-Hamoy L, Castro LD. Age matters but it should not be used to discriminate against the elderly in allocating scarce resources in the context of COVID-19. Asian Bioeth Rev. 2020;16:1-10. https://doi.org/10.1007/s41649020-00130-6.

59. Auriemma CL, Molinero AM, Houtrow AJ, Persad G, White DB, Halpern SD. Eliminating categorical exclusion criteria in crisis standards of care frameworks. Am J Bioeth. 2020;20(7):28-36. https://doi.org/10.1080/ 15265161.2020 .1764141$.

60. Brown TR, Francis LP, Tabery J. Embedding the problems doesn't make them go away. Am J Bioeth. 2020;20(7):109-11. https://doi.org/10.1080/ 15265161.2020 .1779864
61. Boreskie KF, Boreskie PE, Melady D. Age is just a number - and so is frailty: strategies to inform resource allocation during the COVID-19 pandemic. CJEM. 2020;22(4):411-3. https://doi.org/10.1017/cem.2020.358.

62. Onder G, Rezza G, Brusaferro S. Case-fatality rate and characteristics of patients dying in relation to COVID-19 in Italy. JAMA. 2020. https://doi.org/ 10.1001/jama.2020.4683.

63. Maltese G, Corsonello A, Di Rosa M, et al. Frailty and COVID-19: a systematic scoping review. J Clin Med. 2020;9(7):2106. https://doi.org/10.3390/ jcm9072106.

64. Savulescu J, Cameron J, Wilkinson D. Equality or utility? Ethics and law of rationing ventilators. Br J Anaesth. 2020;125(1):10-5. https://doi.org/10.1016/ j.bja.2020.04.011.

65. Archard D, Caplan A. Is it wrong to prioritise younger patients with covid19? BMJ. 2020;369:m1509. https://doi.org/10.1136/bmj.m1509.

66. Davies B. Fair innings and time-relative claims. Bioethics. 2016;30(6):462-8. https://doi.org/10.1111/bioe.12234.

67. Beigi RH, Hodges J, Baldisseri M, English D. Magee-Womens Hospital Ethics Committee. Clinical review: considerations for the triage of maternity care during an influenza pandemic - one institution's approach. Crit Care. 2010; 14(3):225. https://doi.org/10.1186/cc8928.

68. Farrell RM, Beigi RH. Pandemic influenza and pregnancy: an opportunity to reassess maternal bioethics. Am J Public Health. 2009;99(Suppl 2):S231-5. https://doi.org/10.2105/AJPH.2008.140780.

69. Putra M, Kesavan MM, Brackney K, Hackney DN, Roosa MKM. Forecasting the impact of coronavirus disease during delivery hospitalization: an aid for resources utilization. Am J Obstet Gynecol MFM 2020;100127; doi: https:// doi.org/10.1016/j.ajogmf.2020.100127.

70. Sztajnkrycer MD, Madsen BE, Alejandro BA. Unstable ethical plateaus and disaster triage. Emerg Med Clin North Am. 2006;24(3):749-68. https://doi. org/10.1016/j.emc.2006.05.016.

71. Morrow-Howell N, Galucia N, Swinford E. Recovering from the COVID-19 pandemic: a focus on older adults. J Aging Soc Policy. 2020;32:4-5, 526-35. https://doi.org/10.1080/08959420.2020.1759758.

72. Hanschke K, Wolf LE, Hensel WF. The impact of disability: a comparative approach to medical resource allocation in public health emergencies. St Louis U J Health L \& Pol'y. 2015;8:259-314.

73. Campbell VA, Gilyard JA, Sinclair L, Sternberg T, Kailes JI. Preparing for and responding to pandemic influenza: implications for people with disabilities. Am J Public Health. 2009;99(Suppl 2):S294-300. https://doi.org/10.2105/ A.JPH.2009.162677.

74. Tabery J, Mackett CW 3rd; University of Pittsburgh Medical Center Pandemic Influenza Task Force's Triage Review Board. Ethics of triage in the event of an influenza pandemic. Disaster Med Public Health Prep. 2008;2(2):114-8; doi: 10.1097 / DMP.0b013e31816c408b.

75. Persad G, Wertheimer A, Emanuel EJ. Principles for allocation of scarce medical interventions. Lancet. 2009;373(9661):423-31. https://doi.org/10 1016/S0140-6736(09)60137-9.

76. Scheunemann LP, White DB. The ethics and reality of rationing in medicine. Chest. 2011;140(6):1625-32. https://doi.org/10.1378/chest.11-0622.

77. Emanuel EJ, Persad G, Upshur R, et al. Fair allocation of scarce medical resources in the time of COVID-19. N Engl J Med. 2020;382(21):2049-55. https://doi.org/10.1056/NEJMsb2005114.

78. Mill JS. Utilitarismo. Lisboa: Editora Gradiva; 2005

79. Moskop JC, Iserson KV. Triage in medicine, part II: underlying values and principles. Ann Emerg Med. 2007:49(3):282-7. https://doi.org/10.1016/j. annemergmed.2006.07.012.

80. Kerstein SJ. Dignity, disability, and lifespan. J Appl Philos. 2017;34:635-50. https://doi.org/10.1111/japp.12158.

81. Parhar KKS, Lequier L, Blackwood J, Zuege DJ, Singh G. Optimizing provision of extracorporeal life support during the COVID-19 pandemic: practical considerations for Canadian jurisdictions. CMAJ. 2020;192(14):e372-4. https://doi.org/10.1503/cmaj.200448.

82. Weiss MJ, Carnevale F, Rochwerg B, Oczkowski S, Dhanani S. Ensuring nondiscrimination in pandemic prioritization decisions. CMAJ. 2020;192(15): e421. https://doi.org/10.1503/cmaj.75254.

83. Beauchamp TL, Childress JF. Principles of biomedical ethics. New York: Oxford University Press; 2013

84. Cheung W, Myburgh J, McGuinness S, et al. A cross-sectional survey of Australian and New Zealand public opinion on methods totriage intensive care patients in an influenza pandemic. Crit Care Resusc. 2017;19(3):254-65. 
85. Schuklenk U. COVID19: why justice and transparency in hospital triage policies are paramount. Bioethics. 2020;34(4):325-7. https://doi.org/10.1111/ bioe.12744.

86. Piscitello GM, Kapania EM, Miller WD, Rojas JC, Siegler M, Parker WF. Variation in ventilator allocation guidelines by US state during the coronavirus disease 2019 pandemic: a systematic review. JAMA Netw Open. 2020;3(6):e2012606. https://doi.org/10.1001/jamanetworkopen.2020.12606.

87. DeMartino ES, Dudzinski DM, Doyle CK, et al. Who decides when a patient can't? Statutes on alternate decision makers. N Engl J Med. 2017;376(15): 1478-82. https://doi.org/10.1056/NEJMms1611497.

88. Cohen IG, Crespo AM, White DB. Potential legal liability for withdrawing or withholding ventilators during COVID-19: assessing the risks and identifying needed reforms. JAMA. 2020;323(19):1901-2. https://doi.org/10.1001/jama. 2020.5442.

89. Daugherty Biddison EL, Berkowitz KA, Courtney B, et al. Ethical considerations: care of the critically ill and injured during pandemics and disasters: CHEST consensus statement. Chest. 2014;146(Suppl 4):e145S-55S. https://doi.org/10.1378/chest.14-0742.

90. Feito L, Gracia D, Sánchez M, editors. Bioética: el estado de la cuestión. Madrid: Editora Triacastela; 2011.

\section{Publisher's Note}

Springer Nature remains neutral with regard to jurisdictional claims in published maps and institutional affiliations. 